NBER WORKING PAPER SERIES

\title{
ECONOMIC CONDITIONS, ILLICIT DRUG USE, AND SUBSTANCE USE DISORDERS IN THE UNITED STATES
}

\author{
Christopher S. Carpenter \\ Chandler B. McClellan \\ Daniel I. Rees
}

Working Paper 22051

http://www.nber.org/papers/w22051

\author{
NATIONAL BUREAU OF ECONOMIC RESEARCH \\ 1050 Massachusetts Avenue \\ Cambridge, MA 02138 \\ February 2016
}

Carpenter is Professor of Economics at Vanderbilt University, Research Associate at the NBER, and Research Fellow at IZA (Institute for the Study of Labor), christopher.s.carpenter@vanderbilt.edu. McClellan is with the Center for Behavioral Health Statistics and Quality at the Substance Abuse and Mental Health Services Administration (SAMHSA), chandler.mcclellan@samhsa.hhs.gov. Rees is Professor of Economics, University of Colorado Denver and Research Fellow at IZA, daniel.rees@ucdenver.edu. We thank Isaac Swensen and seminar/conference participants at the University of Miami and the 2015 Southern Economic Association for helpful comments. The results in this paper are based on restricted access data from the National Survey on Drug Use and Health. Interested readers can contact the authors for information on how to obtain access. The views expressed herein are those of the authors and do not necessarily reflect the views of SAMHSA or the U.S. Department of Health and Human Services (DHHS). All errors are our own. The views expressed herein are those of the authors and do not necessarily reflect the views of the National Bureau of Economic Research.

NBER working papers are circulated for discussion and comment purposes. They have not been peer-reviewed or been subject to the review by the NBER Board of Directors that accompanies official NBER publications.

(C) 2016 by Christopher S. Carpenter, Chandler B. McClellan, and Daniel I. Rees. All rights reserved. Short sections of text, not to exceed two paragraphs, may be quoted without explicit permission provided that full credit, including (C) notice, is given to the source. 
Economic Conditions, Illicit Drug Use, and Substance Use Disorders in the United States

Christopher S. Carpenter, Chandler B. McClellan, and Daniel I. Rees

NBER Working Paper No. 22051

February 2016

JEL No. E32,I12

\begin{abstract}
$\underline{\text { ABSTRACT }}$
We provide the first analysis of the relationship between economic conditions and the use of illicit drugs other than marijuana. Drawing on US data from 2002-2013, we find mixed evidence with regard to the cyclicality of illicit drug use. However, there is strong evidence that economic downturns lead to increases in substance use disorders involving hallucinogens and prescription pain relievers. These effects are robust to a variety of specification choices and are concentrated among prime-age white males with low educational attainment. We conclude that the returns to spending on the treatment of substance use disorders are particularly high during economic downturns.
\end{abstract}

Christopher S. Carpenter

Department of Economics

Vanderbilt University

VU Station B, Box \#351819

2301 Vanderbilt Place

Nashville, TN 37235

and NBER

christopher.s.carpenter@vanderbilt.edu

Chandler B. McClellan

Center for Behavioral Health Statistics

and Quality (CBHSQ):

Substance Abuse and Mental Health Services

Administration

chandler.mcclellan@gmail.com
Daniel I. Rees

University of Colorado Denver

Department of Economics

Campus Box 181

P.O. Box 173364

Denver, CO 80217-3364

Daniel.Rees@ucdenver.edu 


\section{Introduction}

The United States has recently experienced surges in the prevalence of certain illicit drugs other than marijuana (henceforth illicit drugs), in particular the non-medical use of prescription pain relievers and heroin. From 2001-2013, there was a three-fold increase in overdose deaths involving prescription pain relievers and a five-fold increase in overdose deaths involving heroin (NIDA 2015). Although some observers have attributed these trends, at least in part, to the Great Recession (Farrell 2009; Bernstein et al. 2014; Seelye 2014; Douthat 2015; Mencimer 2015), research on this issue has been hindered by a lack of credible data on illicit drug use at the state-year level. Instead, researchers have focused on how economic conditions affect alcohol, marijuana, and tobacco use, information on which is more readily available.

The current study examines the relationship between economic conditions and the use of illicit drugs such as analgesics (i.e., prescription pain relievers), cocaine, and heroin. Our data source is the National Surveys on Drug Use and Health (NSDUH), which are used to produce the primary estimates of substance use and misuse in the United States (Muhuri et al. 2013). Every year, the NSDUH surveys almost 70,000 residents of the United States about their drug consumption and other health behaviors (Morton et al. 2013). Pooling NSDUH data from the years 2002-2013, we obtain a sample composed of over 800,000 respondents, which is critical for studying illicit drugs with very low rates of use. 
Because the NSDUH questionnaire contains items specifically designed to measure the symptoms of substance use disorder, we are able to study the effects of economic conditions on a variety of clinically relevant outcomes related to substance use disorders, which have been linked to premature mortality from HIV and hepatitis infections, overdoses, suicide, and traffic fatalities (Degenhardt and Hall 2012). ${ }^{1}$ The NSDUH data also span the Great Recession of 2007-2008, allowing us to explore how one of the most severe economic downturns in the past century influenced the use and abuse of illicit drugs.

Documenting the relationship between economic conditions and the use of illicit drugs is important for several reasons. First, theory does not provide clear predictions with regard to how macroeconomic fluctuations relate to substance use (Arkes 2011), and the results of previous studies have been mixed (Pabilonia 2014, Tekin et al. 2013). Second, public funding for drug treatment programs is often at risk of being cut when state and local governments are faced with budget shortfalls (Richman 2009; Dresser 2015; Keilman 2015; McNamara 2015). Accurately predicting the consequences of such cuts requires a better understanding of how economic conditions relate to substance use and abuse. ${ }^{2}$

\footnotetext{
${ }^{1}$ The NSDUH items designed to measure substance use disorder are described below and are based on the criteria contained in the fourth edition of the Diagnostic and Statistical Manual of Mental Disorders (DSM-4).

${ }^{2}$ Accurately predicting the consequences of funding cuts to drug treatment programs also depends upon knowing something about the effectiveness of these programs. Several well-designed studies have concluded that treatment in both outpatient and residential programs leads to substantial and long-lasting reductions in substance use (Hubbard et al. 1997; Simpson et al. 1999; Gossop et al. 2003; Hser et al. 2004). Swensen (2015) uses county level information on substance
} 
Third, there is evidence that deaths from accidental poisoning, or drug overdoses, have become strongly countercyclical since the early 1980s (Ruhm 2015). Ruhm (2015) argued that increased access to opioid analgesics coupled with recessioninduced mental health problems is likely responsible for this phenomenon, but because of lack of data could not explore its causes. Below, we estimate the relationship between economic conditions and the use of prescription pain relievers such as OxyContin and Percocet, providing the first direct support for Ruhm's argument.

Using standard difference-in-differences models, we find that economic downturns are associated with statistically significant increases in the use of ecstasy and reductions in LSD use. Estimates of the relationship between state economic conditions and use of drugs other than ecstasy or LSD are generally inconclusive. Examining outcomes based on more clinically relevant measures of substance use disorder, we find clear evidence that disorders involving analgesics and hallucinogens are strongly countercyclical, substantial in terms of magnitude, and concentrated among non-elderly adult white males with low educational attainment. Taken together, these results provide strong evidence that economic downturns lead to increases in the use and abuse of illicit drugs and suggest that the returns to state and local government spending to treat substance abuse disorders are particularly high during economic downturns.

use treatment facility openings and closings and finds that increases in facilities significantly 
The remainder of this paper proceeds as follows: Section 2 provides a brief literature review, and section 3 describes the data and outlines the empirical approach. Section 4 presents the results, and Section 5 discusses and concludes.

\section{Literature Review}

Our work builds upon a voluminous literature on how health behaviors and health outcomes vary with economic conditions; we provide only a very brief review here, as this work has been summarized elsewhere (Ruhm 2012, Cawley and Ruhm 2012). Since Ruhm's (2000) study showing that mortality in the United States was strongly procyclical, researchers have extended this basic result in several directions. For example, researchers have documented procyclical mortality in other countries (Lin 2009; Gertdham and Ruhm 2006; Tapa Granado 2005) and have explored changes in the relationship between economic conditions and mortality over time (Ruhm 2015). To examine mechanisms, researchers have estimated the effects of macroeconomic conditions on health insurance coverage (Cawley and Simon 2005; Cawley et al. 2015) and healthcare quality (Stevens et

al. 2015, forthcoming). Researchers have also examined how risky health behaviors such as poor diet and nutrition choices respond to macroeconomic fluctuations (Colman and Dave 2014, forthcoming).

reduce drug-induced mortality rates. 
A large number of studies have examined how alcohol consumption varies with the macroeconomy, including methodologically sophisticated studies that control for both time and geography-specific fixed effects. These studies identify the effects of economic conditions by within-area (typically state) changes in the unemployment rate. The broad pattern that emerges from pre-Great Recession business cycles is that heavy drinkers consume less during economic downturns while light drinkers consume more (see Dee 2001, Ruhm 1995, Ruhm and Black 2002, and others; for a recent review see Pacula 2011), although there are some exceptions (Davalos et al. 2012).

Several recent studies have studied the relationship between economic conditions and alcohol consumption using data from the Great Recession. Drawing upon data Behavioral Risk Factor Surveillance System (BRFSS) data, Bor et al. (2013) found that there was an increase in abstention from drinking coupled with an increase in binge drinking during the period 2008-2009. Tekin et al. (2013) also found evidence that binge drinking increased during the Great Recession using BRFSS data, although they argued the effect was trivial in terms of magnitude (that is, they argued that the actual incidence of binge drinking did not increase by an economically significant amount). Finally, recent work by Cotti et al. (2015, forthcoming) using household scanner data found that, among 
households with any alcohol purchases, demand for packaged alcohol was significantly procyclical during the Great Recession. ${ }^{3}$

There have been far fewer studies examining the relationship between economic conditions and illicit drug use, mainly due to the lack of data. In fact, we are aware of only three studies that have examined this relationship using U.S. data, all of which focused on youths and none of which examined specific illicit drugs other than marijuana. ${ }^{4}$ Pabilonia (2014) analyzed YRBS data on 15-17 year-olds for the period 2003-2011. She found little evidence of a relationship between economic conditions and marijuana use among white respondents, although there was a significant countercylical relationship among black males. Arkes $(2007,2011)$ examined drug use among youths and young adults using data from the National Longitudinal Surveys of Youth 1997 (NLSY97). Controlling for unobserved heterogeneity at the state level, he found that the use of marijuana and illicit drugs among teenagers was strongly countercyclical. Among 20-24 year-olds, marijuana use appeared to be countercyclical, but the relationship between economic conditions and illicit drugs was much weaker (Arkes 2011).

\footnotetext{
${ }^{3}$ At least two studies have focused on the relationship between economic conditions and youth drinking. Using Youth Risk Behavior Survey (YRBS) data for the period 1991-2011, Argys et al. (2014) found that drinking participation and binge drinking both increased during economic downturns. In contrast, Pabilonia (2014) did not find evidence of counter cyclicality for drinking among 15-17 year-olds using YRBS data for a shorter period (2003-2011).

${ }^{4}$ We are only aware of one study that has examined economic conditions and drug use using nonU.S. data. Chalmers and Ritter (2011) focused on alcohol and cannabis use in Australia from 1991-2007. These authors found that economic downturns were positively related to the number of youths who used cannabis as well as their frequency of use.
} 
Data limitations did not permit Arkes to separately identify specific illicit drugs, and the relevant question in the NLSY also explicitly excludes use of drugs prescribed by physicians, which is of particular interest to public health officials in light of the increase in prescription drug misuse. ${ }^{5}$ As we will show below: 1) the relationship between economic conditions and substance use differs markedly across drug types; 2) the use of some drugs (e.g., LSD) is procyclical while use of others is countercyclical (e.g., ecstasy), suggesting that an aggregate 'any illicit drug' outcome could mask important relationships; and 3) there is a strong relationship between economic conditions and prescription pain relievers that likely would not be included in the NLSY measure. These patterns - along with our disorder outcomes described in detail below - highlight the unique value of the NSDUH data.

To summarize, while there are numerous well-designed studies that evaluate the effects of economic conditions on alcohol consumption among both adults and youths, there are only three studies that have examined population rates of illicit drug use, all of which focused on teenagers or young adults and only one of which used data spanning the Great Recession. ${ }^{6}$ None of the prior work on

\footnotetext{
${ }^{5}$ Specifically, individuals are asked: "Excluding cannabis and alcohol, since the date of the last interview, have you used any drugs like cocaine or crack or heroin, or any other substance not prescribed by a doctor, in order to get high or achieve an altered state?”

${ }^{6}$ Maclean et al. (2013) used data from the Treatment Episodes Data Set (TEDS) for the period 1992-2010 to examine the relationship between economic conditions and admissions to specialty substance abuse treatment facilities for alcohol and illicit drugs. They found that both alcohol and drug treatment admissions declined during economic downturns, but could not rule out the possibility that "reductions in (substance abuse) treatment supply mechanically lower admissions"
} 
illicit drugs examines substance use disorder as based on professionallydeveloped diagnostic criteria ${ }^{7}$, an outcome that is more clinically relevant than simple participation. Our study fills these gaps by using NSDUH data to provide the first comprehensive evidence on the relationship between economic conditions and the use of specific illicit drugs, and by providing the first estimates of the relationship between economic conditions and substance use disorders.

\section{Data Description and Empirical Approach}

As noted above, our primary data source is the National Survey on Drug Use and Health (NSDUH); we use restricted versions from 2002-2013. ${ }^{8}$ The federal government uses these data for determining drug use prevalence in the United States. The NSDUH is a survey of individuals in non-institutional settings and was designed to be representative at the state level.

NSDUH respondents are asked a series of questions about their use of tobacco, alcohol, marijuana, and illicit drugs, including prescription painkillers. Specifically, NSDUH respondents are asked: "Now think about the past 12 months, from [DATEFILL] through today. We want to know how many days

(p. 14). Substance abuse treatment use may respond differentially than that of other healthcare because income effects, which appear to dominate general healthcare utilization decisions during downturns, may be more than offset by true need for substance abuse treatment (i.e., psychological stress related to downturns can lead individuals to misuse substances).

${ }^{7}$ Davalos et al. (2012) examine alcohol use and/or dependence (using the DSM-4 criteria) with data from Waves 1 and 2 of the National Epidemiologic Survey on Alcohol Related Conditions (NESARC). They find that higher state unemployment rates are significantly related to increased likelihood of alcohol abuse and/or dependence. 
you've used \{drug \} during the past 12 months."9 Based on answers to these questions, NSDUH statisticians create participation indicators, which are defined as equal to one if the respondent reported any past year use of the relevant substance and equal to zero otherwise. The survey also identifies whether the substance use occurred in the past month, and we create associated indicators for more recent use accordingly.

We examine several outcomes reflecting different groupings of drugs based on well-accepted classifications. For alcohol and marijuana, we measure any past month and past year use of each substance. For illicit drugs, we first consider a broad participation indicator equal to one if a respondent reported taking any drug other than alcohol, tobacco, or marijuana in the prior year (including prescription painkillers), which we call 'Any Illicit Drug Use'. We then separate illicit drugs into 7 mutually exclusive categories: cocaine (including crack); other stimulants (including methamphetamine); analgesics (i.e., prescription pain relievers); heroin; sedatives and tranquilizers; hallucinogens; and inhalants. Table 1 reports mean participation by these 7 categories.

Stimulants are drugs such as cocaine and 'meth' that stimulate or accelerate the central nervous system. Analgesics are drugs used to relieve pain, and sedatives/tranquilizers are drugs with a sedating effect on the central nervous

\footnotetext{
${ }^{8}$ NSDUH underwent a major redesign between 2001 and 2002; earlier waves are not comparable.
} 
system. ${ }^{10}$ Within the category of analgesics we consider oxycontin separately. Hallucinogens are drugs that produce hallucinations when taken; so-called "club drugs” such as Special K, LSD, and ecstasy fall into this category. Within hallucinogens we separately consider LSD, PCP, and ecstasy. Inhalants comprise a broad class of substances such as gases, solvents, aerosols, and nitrites that produce mind-altering effects and share a common route of administration (i.e., breathing them in); there are no subcategories for inhalants or heroin.

In addition to recent use, which is the focus of most prior research, a major strength of the NSDUH is that it also asks respondents a series of questions about abuse and dependence of various substances (alcohol, marijuana, cocaine, heroin, hallucinogens, inhalants, pain relievers, tranquilizers, stimulants, and sedatives) over the past year. These include the following problems related to use of the substance: 1) hazardous use; 2) social/interpersonal problems related to use; 3) neglected major roles to use; 4) withdrawal (not defined for cannabis, inhalants, or hallucinogens); 4) tolerance; 5) used larger amounts/longer; 6) repeated attempts to quit/control use; 7) great deal of time spent using or in associated activities; 8) physical/psychological problems related to use; and 9) activities

\footnotetext{
${ }^{9}$ Many drugs have multiple 'street names'; the survey instrument uses these alternate names in attempting to measure drug use prevalence. Although all of the drug use outcomes are selfreported, these data have been validated by other research (SAMHSA 2012).

${ }^{10}$ The wording of the NSDUH questionnaire does not allow us to distinguish the use of opioid analgesics from the use of non-opioid analgesics such as Fioricet and Fiorinal. However, NSDUH respondents are asked to identify which prescription drug they have ever used. The use of nonopioid prescription pain relievers appears to be at extremely lows levels: only 0.14 and 0.11 percent of respondents indicate any lifetime use of Fioricet and Fiorinal (respectively) in 2013.
} 
given up to use. A recent substantive update to the Diagnostic and Statistical Manual of Mental Disorders (DSM-5) no longer differentiates between abuse and dependence, but instead adopts a substance use disorder rubric that combines elements of each and places the disorder on a severity continuum (Hasin et al. 2013). While future NSDUH questionnaires will have DSM-5 criteria for a revised set of questions as part of a larger redesign of the survey, only DSM-4 criteria are currently available. To reflect the new understanding that substance use disorder is not separable into abuse and dependence, but should be viewed on a continuum, we use the DSM-4 diagnostic criteria that overlap with the DSM-5 criteria for questions asked during the period 2002-2013 to calculate a substance use disorder estimate that attempts to be consistent with the current DSM-5 algorithm $^{11}$.

Specifically, we define an individual as having a substance use disorder if the respondent reported fulfilling two or more criteria of the DSM-4. In addition, we follow DSM-5 classification scheme by separately examining mild substance use disorder ( 2 or 3 criteria), moderate substance use disorder ( 4 or 5 criteria), and severe substance use disorder (6 or more criteria). Although slightly different from the DSM-5 measure, these measures anticipate the DSM-5 changes allowing

\footnotetext{
11 The DSM-4 and DSM-5 share nearly all substance disorder criteria. Notably, the DSM-5 classification removes a 'legal problems' criterion and adds a 'craving' criterion. The major change between the versions is how those criteria are classified into certain diagnoses. Since the NSDUH does not include questions for the 'craving' criterion, we denote our measure as a 'pseudo' substance abuse diagnosis measure.
} 
us to extend the analysis from simple use patterns to the more consequential outcomes of substance use dependence. Because the NSDUH does not include the craving measure in the DSM-5, we will underestimate substance use disorders based on these criteria. However, this measurement error should not be systematically related to economic conditions.

To estimate the effects of economic conditions on the outcomes described above, we estimate standard two-way fixed effects models that rely on plausibly exogenous variation in the timing and extent of macroeconomic fluctuations across states. Specifically, we estimate:

(1) $Y_{i s t}=\pi_{0}+\pi_{1}$ State Unemployment Rate Rt $+\boldsymbol{X}_{i s} \boldsymbol{\beta}+v_{s}+w_{t}+\theta_{s} t+\varepsilon_{i s t}$ where $Y_{i s t}$ are the substance use and disorder outcomes available in the NSDUH data for individual $i$ in state $s$ at time $t$. Because some drug participation rates are very low (i.e., near the 0 boundary), we estimate logistic regression models on the dichotomous NSDUH outcomes and report marginal effects evaluated at the sample means. $\boldsymbol{X}_{i s t}$ is a vector of individual characteristics available in the NSDUH, including: gender, age, race, ethnicity, education, family income, and marital status. State Unemployment Rate $_{s t}$ is the twelve month moving average of the monthly state unemployment rate prior to the month of the interview date from the Bureau of Labor Statistics; this is a standard approach in the literature 
(Tekin et al. 2013). ${ }^{12}$ In some specifications, we allow for state-specific linear time trends by interacting a linear trend variable (equal to 1 in 2002, 2 in 2003, and so forth) with the state fixed effects. Standard errors are corrected for clustering at the state level (Bertrand et al. 2004).

\section{Results}

\section{a. Descriptive Statistics, Substance Use Outcomes and Demographics}

We begin by presenting descriptive statistics on drug use in Table 1. Columns 14 present weighted means for past month use, past year use, past year disorder, and past year disorder conditional on past year use, respectively, for each substance.

Alcohol and marijuana are by far the most commonly used substances in the US population. Two thirds of the population reported consuming alcohol in the past year, and 11 percent reported consuming marijuana. In comparison, 8 percent reported using any illicit drug other than marijuana in the past year, with nearly 5 percent reporting the use of analgesics.

Turning to substance use disorder, we find that 8 percent of the population meets the criteria for having a clinically relevant alcohol use disorder, while 1.65 percent of the population had a substance use disorder for an illicit drug. Column

\footnotetext{
${ }^{12}$ In robustness analyses, we explore models that replace the state unemployment rate with the state employment to population ratio or state per capita GDP, and we also explore models that measure the unemployment rate at the county level as opposed to the state level.
} 
4 reveals that substance use disorders are very common among past-year users of each substance. For example, while only 0.14 percent of the population reported having used heroin in the past year, fully 61 percent of past year heroin users meet the pseudo DSM-5 definition for disorder. Similarly, while only 0.28 percent of the population reported using sedatives and tranquilizers, nearly 68 percent of past year users met the definition for disorder. Thus, while the prevalence of past year use of illicit drugs is rare, clinical disorder is very common among past year substance users.

Table 2 presents means for the individual demographic characteristics and state unemployment rate. The majority is white, non-elderly adult (18-64), and employed, with about half the population having at least some college education and about half being married. The average state unemployment rate over this period was approximately 6.7 percent.

\section{b. Results: Economic conditions and substance use}

We begin the discussion of our results with the results for substance use, followed by results for substance use disorder, and concluding with results from several extensions, robustness checks, and heterogeneous sub-populations. Table 3 shows our main results on the relationship between economic conditions and substance use for the major drug categories. Each entry in Table 3 is the coefficient on the state unemployment rate variable in a model that includes 
controls for all the individual demographic characteristics and state and year fixed effects. In columns (2) and (4) of Table 3, we include state-specific linear trends as additional controls. In columns (1) and (2), we report results for past-month outcomes, while in columns (3) and (4) we report results for past-year outcomes.

For alcohol, which has been the subject of most prior work on this topic, there is some evidence of a procyclical relationship. Specifically, three out of four estimates of $\boldsymbol{\pi}_{\boldsymbol{1}}$ are negative, but only one is significant at conventional levels: controlling for state-specific trends, a one percentage point increase in the unemployment rate is associated with a decrease in the probability of past-month alcohol participation of .0034 . Estimates of $\boldsymbol{\pi}_{1}$ for marijuana use are small and statistically insignificant. Similarly, when we consider the use of any illicit drug in the third row of Table 3, there is no evidence of a relationship with state unemployment rates using either past-month or past-year outcomes.

The general pattern of null findings is repeated when we turn our attention to the major drug classes. For example, we find no statistically or economically meaningful relationships between state economic conditions and use of analgesics, sedatives and tranquilizers, or inhalants using either past year or past month measures. We do, however, find a statistically significant procyclical relationship for stimulants using past-month measures, although the past-year relationships are not statistically significant. We also find a statistically significant countercyclical relationship for hallucinogens using both the past- 
month and past-year measures (although the past-month relationship is not robust to including state trends).

In Table 4, we focus on several drug subcategories (e.g., LSD and PCP instead of the broad category of hallucinogens). The most consistent finding in Table 4 is that ecstasy use is strongly countercyclical: coefficient estimates on the state unemployment rate for both past-month and past-year use are positive, statistically significant, and robust to the inclusion of state trends. Specifically, controlling for state-specific linear trends, a one- percentage point increase in the state unemployment rate is associated with a .00049 increase in the probability of ecstasy use in the past year, or a five percent increase relative to the mean $(.049 / .98=.05)$. Results in Table 4 also indicate that past-month LSD use is significantly procyclical, and this relationship holds when examining past-year use in the model with state trends. There is also some evidence of a procyclical relationship for PCP, although these results only hold in models with statespecific trends. Overall, the results in Table 4 indicate that ecstasy use is strongly countercyclical, LSD use is strongly procyclical, and other subcategories of illicit drugs exhibit a less consistent relationship with state unemployment rates. ${ }^{13}$

\footnotetext{
13 These same general patterns (i.e., mixed evidence on use) remained when we examined outcomes reflecting 'regular' use, such as the probability of reporting at least four uses in the past month (i.e., approximately once per week) or the probability of reporting at least 12 uses in the past year (i.e., approximately once per month). These results are available upon request.
} 


\section{c. Results: Economic conditions and substance use disorder}

In Table 5, we turn to our attention to substance use disorders. Recall that the disorder questions were only asked regarding outcomes over the past year for the major drug classes. Results in Table 5 indicate that substance use disorders for most major drug classes are not related to economic conditions. Estimated coefficients of the state unemployment rate for disorders involving marijuana, cocaine, stimulants, heroin, sedatives and tranquilizers, and inhalants are consistently small and statistically insignificant. There is some evidence of a statistically significant countercyclical relationship for alcohol disorders, although this estimate is not significant in the model with linear state trends.

Table 5 also indicates that disorders involving the use of analgesics and hallucinogens are significantly countercyclical: controlling for state-specific linear trends, a one percentage point increase in the state unemployment rate is associated with an increase in the probability of having a disorder involving analgesics of .00049 and increase in the probability of having a disorder involving hallucinogens of .00017. For each percentage point increase in the state unemployment rate, these estimates represent about a six percent increase in the likelihood of having a disorder involving analgesics and an 11 percent increase in the likelihood of having a disorder involving hallucinogens.

Next, we investigate robustness of, and extensions to, the key findings on analgesics and hallucinogens disorders documented in Table 5. These results are 
reported in Table 6, which shows the results of several extensions and robustness analyses in the rows. In each row, we report the coefficient of the relevant economic-conditions variable for analgesics disorder in columns (1) and (2) (with and without trends, respectively) and for hallucinogens disorder in columns (3) and (4).

In the first row of Table 6, we report the baseline estimate from Table 5 documenting that analgesics and hallucinogens disorders are strongly countercyclical. Rows (2)-(4) show results separately for mild, moderate, and severe disorders. ${ }^{14}$ These results are somewhat sensitive to the inclusion of statespecific linear trends, although severe disorders involving hallucinogens are clearly countercyclical with or without controlling for state trends. In row (5), we again focus on any disorder, but we restrict our attention to individuals whose NSDUH responses were not imputed to check if SAMHSA imputation procedures impart any bias to the outcomes. This affects very small share of observations in the sample with either missing data or logical imputations performed on their substance use responses; in each case, the estimated coefficient on the state unemployment rate is nearly identical to the baseline estimate in row (1). In row (6), we restrict the sample to past-year users of each substance and find that

\footnotetext{
${ }^{14}$ Severity of dependence is determined by the number of dependence criteria the individual meets, with 2-3 criteria indicating mild dependence, 4-5 indicating moderate dependence, and 6 or more indicating severe dependence.
} 
positive relationship between the unemployment rate and disorders involving analgesics remains.

In rows (7) and (8) of Table 6, we explore alternative estimation strategies and show that the findings with regard to analgesics and heroin disorders are robust to using either a linear probability model or a probit. In rows (9) and (10), we explore other ways to measure state economic conditions. ${ }^{15}$ Although state unemployment rates are standard in the literature, we also examine state employment to population ratios in row (9) and state log GDP per capita in row (10). The results of this exercise suggest that our findings are generally robust to alternative choices of specification with respect to expected sign and magnitude, but statistical significance is affected in rows (9) and (10) for analgesics and hallucinogens, respectively. ${ }^{16}$ Finally, in row (11) we show that our results are similar to outcomes using the DSM-4 classification of abuse and dependence. ${ }^{17}$

\footnotetext{
${ }^{15}$ We also examined whether the level of aggregation matters for our estimates by measuring economic conditions using county (as opposed to state) unemployment rates (Lindo 2015). Notably, in these models we also replaced the state fixed effects with county fixed effects. Results indicated that aggregation choices do not alter our core finding that higher unemployment rates are associated with significant increases in substance use disorders involving analgesics and hallucinogens. These results are available upon request.

16 We also estimated similarly specified differences-in-differences models relating state unemployment rates to the likelihood an individual reports she is employed and to the respondent's reported household income. State unemployment rates were statistically significant (negative) predictors of each. These results are available upon request.

${ }_{17}$ The NSDUH also asks whether individuals sought treatment for substance use abuse or dependence in the prior year. In results not reported but available upon request, we did not find statistically significant relationships between state economic conditions and the likelihood of seeking treatment for substance use disorders.
} 
d. Results: Economic conditions and substance use in heterogeneous subpopulations

In Table 7, we take our core findings on analgesics and hallucinogen disorders and estimate models separately by demographic characteristics to examine possible differential treatment effects on sub-populations. The format of Table 7 follows that of Table 6: in the top row we reprint the main estimates from Table 5 for analgesics and hallucinogens. The subsequent rows of Table 7 report results from estimation of equation (1) separately for: men, women, whites, nonwhites, individuals with a high school degree or less, individuals with some college or more, individuals under the age of 18, individuals age 18-64, and individuals in the 15 states with the highest use rates of each drug. ${ }^{18}$ The results show that state unemployment rates are significantly positively related to analgesics and hallucinogens disorders for men, whites, less educated individuals, and 18-64 year olds. ${ }^{19}$

\footnotetext{
${ }^{18}$ We also examined whether the disorder results varied according to the individual's reported occupation. Interpretation of these analyses is complicated by the fact that economic conditions change who is employed (and thus who is reporting an occupation), but we did find robust evidence that the countercyclical relationship for substance use disorders involving analgesics is driven by people in sales/service occupations as opposed to professionals or blue collar workers. Notably, we also found that among blue collar workers (construction, maintenance, machine operators, transportation workers, and the armed forces), substance use disorders involving heroin were also strongly countercyclical. These results are available upon request.

${ }^{19}$ We also estimated models for individuals age 65 and older. Estimates of the effect of state unemployment rates on substance use disorders involving analgesics were not statistically significant, and there were too few individuals age 65 and older who reported using hallucinogens to meaningfully estimate similar models for that outcome. We also estimated models separately for 18-34 year olds and 35-64 year olds but did not find robust differences in the effects across these age groups for disorders involving analgesics or hallucinogens. We did, however, find that higher state unemployment rates were significantly related to increases in the likelihood of both
} 
In row (10) of Table 7, we restrict our attention to NSDUH respondents from the 15 states with the highest participation rates for the period 2002-2013. This restriction is intended to address the concern that use of these drugs may be highly regional - and thus that many states are mainly contributing noise to the relationship between economic conditions and the outcomes under study. When we restrict our attention to the 15 states with the highest rates of hallucinogen use, we find that disorders involving hallucinogens are still significantly countercyclical; when we restrict our attention to the 15 states with the highest rates of analgesics use, the estimated relationship between the unemployment rate and disorders involving analgesics is positive with or without state-specific trends, but only significant in column (1). ${ }^{20}$

\section{e. Did the Great Recession change these relationships?}

Having demonstrated that disorders relating to analgesics and hallucinogens were strongly countercyclical over the period 2002-2013, we now ask whether the Great Recession occasioned a change in the relationship between the unemployment rate and these disorders. That is, we ask whether the association

heroin use and heroin-related substance use disorders for 18-34 year olds, consistent with the results for blue collar workers described above. These results are available upon request.

${ }^{20}$ For analgesics, the 15 states with the highest rates of use are: West Virginia, Idaho, Michigan, Alabama, New Mexico, Rhode Island, Arizona, Colorado, Nevada, Arkansas, Indiana, Kentucky, Washington, Oregon, and Oklahoma. For hallucinogens, the 15 states with the highest rates of use are: California, Connecticut, Arizona, Nevada, Maine, Massachusetts, Washington, Alaska, New Mexico, Rhode Island, New Hampshire, Montana, Oregon, Vermont, and Colorado. 
between the unemployment rate and these disorders was more (or less) pronounced during the period December 2007 - June 2009, when the United States experienced one of the most pronounced recessions in its history. Specifically, we modify equation (1) by adding a control for whether the respondent reported on substance use behavior that would have occurred between December 2007 and June 2009, as well as an interaction between the state unemployment rate and the Great Recession indicator:

(2) $Y_{i s t}=\pi_{0}+\pi_{1}$ State Unemployment Rate St $+\pi_{2}$ Great Recession $_{t}+\pi_{3}($ State Unemployment Rate $^{*}$ Great Recession $)_{s t}+X \beta_{i s t}+v_{s}+w_{t}+\theta_{s} t+\varepsilon_{i s t}$, where all variables are as defined above. If the relationship changed fundamentally during the recession, we would expect it to be observed on the interaction term between the unemployment rates and the Great Recession.

We present the results of this exercise in Table 8 for analgesics disorder (column 1) and hallucinogens disorder (column 2). For both outcomes, we confirm the countercyclicality of disorder but fail to find meaningful interactions between unemployment rates and the Great Recession period. This suggests that although economic conditions play a strong role in substance use disorder, the Great Recession period did not fundamentally alter this relationship.

\section{Discussion and Conclusion}


The results above provide the first comprehensive evidence on economic conditions and illicit drug use in the United States. We overcome inherent data limitations of prior work by using restricted data from the 2002-2013 National Surveys on Drug Use and Health (NSDUH) and standard two-way fixed effects models of illicit drug use and abuse. Prior work has focused nearly exclusively on alcohol, marijuana, or used a broad categorization of 'any illicit drug'; NSDUH data allow us to examine all major drug classes as well as specific subcategories of illicit drugs. Results from difference-in-differences models relating past year use to past year state unemployment rates provide evidence that recent use of ecstasy is significantly countercyclical, while LSD use is significantly procyclical. Results for other classes of drugs are mixed and not consistent.

Our most important results concern clinically meaningful NSDUH outcomes relating to substance use disorders that are based on (though not identical to) DSM-5 criteria such as withdrawal, physical/psychological problems related to use, and hazardous use. To our knowledge, no prior study has linked economic conditions to substance use disorders for illicit drugs. Individuals with substance use disorders comprise the disproportionate share of social costs associated with illicit drug use and represent the main targets of substance use treatment (Degenhardt and Hall 2012). We find clear evidence that substance use disorders involving analgesics and hallucinogens are both strongly 
countercyclical. These findings, which are highly robust and strongest among non-elderly adult white men with low levels of education (who were hit hard by recent economic downturns), are consistent with the observation that deaths from accidental poisoning have become strongly countercyclical since the 1980s (Ruhm 2015).

Our results are important for understanding optimal policy responses to economic booms and busts. Most debates over public funding for drug treatment, penalties for illicit drug use, and other drug policy levers ignore the role of economic conditions. Our results highlight the perils of this omission. For example, as state budgets contract during economic downturns, drug treatment funding is particularly vulnerable. Our findings suggest that such funding cuts, if untargeted, could lead to significant adverse effects on individuals with substance use disorders. 


\section{BIBLIOGRAPHY}

Argys, Laura M., M. Melinda Pitts, and Astha Sen (2014). “Do Recessions Rein in Your Teen?” working paper.

Arkes, Jeremy (2007). “Does the Economy Affect Teenage Substance Use?” Health Economics, 16: 19-36.

----- (2011). "Recessions and the Participation of Youth in the Selling and Use of Illicit Drugs,” International Journal of Drug Policy, 22(5): 335-340.

Bernstein, Lenny Lena H. Sun and Sandhya Somashekhar (2014). "Robin Williams's Death Shows the Power of Depression and the Impulsiveness of Suicide," The Washington Post, August 12, 2014. Available at: http://www.washingtonpost.com/news/to-yourhealth/wp/2014/08/12/robin-williamss-death-shows-the-power-ofdepression-and-the-impulsiveness-of-suicide/

Bor, Jacob, Sanjay Basu, Adam Coutts, Martin McKee, and David Stuckler (2013). “Alcohol use during the Great Recession of 2008-2009," Alcohol and Alcoholism, 48(3): 1-6.

Cawley, John, Asako S. Moriya, and Kosali Simon (2015). "The Impact of the Macroeconomy on Health Insurance Coverage: Evidence from the Great Recession,” Health Economics, 24(2): 206-223.

Cawley, John and Christopher Ruhm (2012). “The Economics of Risky Health Behaviors.” In Handbook of Health Economics, Volume 2, Mark V. Pauly, Thomas G. Mcguire, and Pedro P. Barros, Eds. North Holland.

Cawley, John and Kosali Simon (2005). "Health insurance Coverage and the Macroeconomy,” Journal of Health Economics, 24: 299-315.

Chalmers, Jenny and Alison Ritter (2011). “The Business Cycle and Drug Use in Australia: Evidence from Repeated Cross-sections of Individual Level Data,” International Journal of Drug Policy, 22(5): 341-352.

Colman, Gregory and Dhaval Dave (2014 forthcoming). "Unemployment and Health Behaviors over the Business Cycle: A Longitudinal View,” Social Science \& Medicine, forthcoming. 
Cotti, Chad, Richard A. Dunn, and Nathan Tefft (2014, forthcoming). “The Great Recession and Consumer Demand for Alcohol: A Dynamic Panel-Data Analysis of U.S. Households," American Journal of Health Economics.

Davalos, Maria E., Hai Fang, and Michael T. French (2012). "Easing the Pain of an Economic Downturn: Macroeconomic Conditions and Excessive Alcohol Consumption," Health Economics, 21: 1318-1335.

Dee, Thomas (2001). "Alcohol Abuse and Economic Conditions: Evidence from Repeated Cross-Sections of Individuals," Health Economics, 10: 257-270.

Degenhardt, Louisa, and Wayne Hall (2012). "Extent of illicit drug use and dependence, and their contribution to the global burden of disease." The Lancet, 379.9810: 55-70.

Douthat, Ross (2015). “The Dying of the Whites," The New York Times, November 7, 2015.2 Available at: http://www.nytimes.com/2015/11/08/opinion/sunday/the-dying-of-thewhites.html

Dresser, Michael (2015). "Supporters of Mental Health, Drug Treatment Providers Rally for Funds,” The Baltimore Sun, February 25, 2015. Available at: http://www.baltimoresun.com/news/maryland/politics/blog/bal-supportersof-mental-health-drug-treatment-providers-rally-for-funds-20150225story.html

Farrell, Michael B. (2009). "Heroin's Comeback: Busts at Levels not Seen since the '70s." The Christian Science Monitor, August 5, 2009. Available at: http://www.csmonitor.com/USA/Society/2009/0805/p02s07-ussc.html

French, Michael T. and Gulcin Gumus (2014). "Macroeconomic Fluctuations and Motorcycle Fatalities in the US," Social Science \& Medicine, 104: 187193.

Gerdtham, Ulf-G and Christopher J. Ruhm (2006). "Deaths Rise in Good Economic Times: Evidence from the OECD," Economics and Human Biology, 43(3): 298-316. 
Gossop, Michael, John Marsden, Duncan Stewart, and Tara Kidd (2003). “The National Treatment Outcome Research Study (NTORS): 4-5 Year Follow-Up Results,” Addiction, 98 (3) 291-303.

Hasin, Deborah S., Charles P. O'Brien, Marc Auriacombe, Guilherme Borges, Kathleen Buchholz, Alan Budney, Wilson M. Compton, Thomas Crowley, Walter Ling, Nancy M. Petry, Marc Schuckit, and Bridget F. Grant (2013). "DSM-5 Criteria for Substance Use Disorders: Recommendations and Rationale," American Journal of Psychiatry, 170(8): 834-851.

Hser, Yih-Ing Elizabeth Evans, David Huang, and Douglas M. Anglin (2004). "Relationship between Drug Treatment Services, Retention, and Outcomes," Psychiatric Services, 55 (7): 767-774.

Hubbard, Robert L., S. Gail Craddock, Patrick M. Flynn, Jill Anderson, and Rose M. Etheridge (1997). "Outcomes of 1-Year Follow-Up Outcomes in the Drug Abuse Treatment Outcome Study (DATOS)," Psychology of Addictive Behaviors, 11 (4): 261-278.

Jones, Christopher M, Joseph Logan, Matthew Gladden, and Michele K. Bohm (2015). "Vital Signs: Demographic and Substance Use Trends Among Heroin Users - United States, 2002-2013. Morbidity and Mortality Weekly Report, 64(26): 719-725.

Keilman, John (2015). "Report: State-Funded Drug Aid Dries up as Chicago's Heroin Problem Worsens," Chicago Tribune, August 11, 2015. Available at: http://www.chicagotribune.com/news/ct-heroin-treatment-cuts-met20150810-story.html

Laufenberg, Jeff, Larry Kroutil, Peter Frechtel, Lisa Carpenter, Susan Edwards, Glynis Ewing, Kristen Gulledge, Wafa Handley, Peilan Martin, Andrew Moore, and Victoria Scott (2012). "2012 National Sruvey on Drug Use and Health: Editing and Imputation Report,” Report prepared for the 2012 Methodolgical Resource Book, Deliverable No. 41.

Lin, Shin-Jong (2009). "Economic Fluctuations and Health Outcome: A Panel Analysis of Asia-Pacific Countries,” Applied Economics, 41(4): 519-530.

Lindo, Jason (2015). "Aggregation and the estimated effects of economic conditions on health," Journal of Health Economics, 40: 83-96. 
McNamara, Patrick (2015). "Budget Cuts threaten Pima County Court Programs," Tucson.com, March 30, 2015. Available at: http://tucson.com/news/local/budget-cuts-threaten-pima-county-courtprograms/article_b751a168-d766-11e4-9590-a33edc0e0bb1.html

Maclean, Johanna Catherine, Jonathan H. Cantor, and Rosalie Liccardo Pacula (2015). "Economic Downturns and Substance Abuse Treatment: Evidence from Admissions Data.” NBER Working Paper No. 19115.

Mencimer, Stephanie (2015). "More American White Women Are Dying Prematurely." Mother Jones, March 5, 2015. Available at: http://www.motherjones.com/politics/2015/03/more-american-whitewomen-dying-prematurely

Mocan, Naci and Daniel Rees (2005). "Economic Conditions, Deterrence and Juvenile Crime: Evidence from Micro Data," American Law and Economics Review, 7: 319-349.

Morton, Katherine, Peilan Martin, Bonnie Shook-Sa, James Chromy, Erica Hirsch. (2013). "2012 National Survey on Drug Use and Health: Sample Design Report,” 2012 Methodological Resource Book, Substance Abuse and Mental Health Services Administration. January 2013.

Muhuri, Pradip K., Joseph C. Gfroerer, and M. Christine Davies (2013). "Associations of Nonmedical Pain Reliever Use and Initiation of Heroin Use in the United States," SAMHSA Center for Behavioral Health Statistics and Quality Data Review, August 2013.

National Institute on Drug Abuse (NIDA) (2015). Overdose Death Rates. Available at: http://www.drugabuse.gov/related-topics/trendsstatistics/overdose-death-rates

Pabilonia, Sabrina Wulff (2014). "The Effects of the Great Recession on Teenagers’ Risky Health Behaviors and Time Use,” BLS Working Paper \#474.

Pacula, Rosalie Liccardo (2011). "Substance Use and Recessions: What Can be Learned from Economic Analyses of Alcohol?” International Journal of Drug Policy, 22(5): 326-334. 
Richman, Josh (2009). "California Cuts of Prop. 36 Drug Treatment Funding Called 'A Harm that Keeps on Hurting'," San Jose Mercury News, July 29, 2009. Available at: http://www.mercurynews.com/californiabudget/ci_12938212?nclick_check

Ruhm, Christopher (2015). "Recessions, healthy no more?” Journal of Health Economics, 42: 17-28.

----- (2012). "Understanding the Relationship between Macroeconomic Conditions and Health.” In The Elgar Companion to Health Economics, $2^{\text {nd }}$ Edition. Andrew M. Jones, Ed. Cheltenham, UK: Edward Elgar Publishing, 2012, 5-14.

----- (2000). “Are Recessions Good for Your Health?” Quarterly Journal of Economics, 115: 617-650.

----- (1995). “Economic Conditions and Alcohol Problems,” Journal of Health Economics, 14: 583-603.

Ruhm, Christopher and William Black (2002). "Does Drinking Really Decrease in Bad Times?” Journal of Health Economics, 21: 659-678.

Seelye, Katharine Q. (2015). "Obituaries Shed Euphemisms to Chronicle Toll of Heroin,” The New York Times, July 11, 2015.

Simpson, D. Dwayne, George W. Joe, Bennett W. Fletcher, Robert L. Hubbard, M. Douglas Anglin (1999). "A National Evaluation of Treatment Outcomes for Cocaine Dependence," Archives of General Psychiatry, 56(6): 507-514.

Stevens, Ann Huff, Douglas L. Miller, Marianne E. Page, and Mateusz Filipski (2015, forthcoming). "The Best of Times, the Worst of Times: Understanding Pro-Cyclical Mortality,” American Economic Journal: Economic Policy.

Substance Abuse and Mental Health Services Administration (SAMHSA) (2012). Comparing and evaluating youth substance use estimates from the National Survey on Drug Use and Health and other surveys, HHS Publication No. SMA 12-4727, Methodology Series M-9. Rockville, MD: Substance Abuse and Mental Health Services Administration. 
(2013). "Results from the 2012 National Survey on Drug Use and Health: Summary of National Findings," NSDUH Series H-46, HHS Publication No. (SMA) 13-4795. Rockville, MD: Substance Abuse and Mental Health Services Administration.

Swensen, Isaac D. (2015). “Substance-abuse treatment and mortality,” Journal of Public Economics, 122: 13-30.

Tapa Granados, Jose (2005). "Recessions and Mortality in Spain, 1980-1997," European Journal of Population, 21(4): 393-422.

Tekin, Erdal, Chandler McClellan, and Karen Jean Minyard (2013). "Health and Health Behaviors During the Worst of Times: Evidence from the Great Recession,” NBER Working Paper \#19234. 
Table 1: Means, Substance Use Outcomes

\begin{tabular}{|c|c|c|c|c|}
\hline & $\begin{array}{c}\text { (1) } \\
\text { Past month } \\
\text { participation }\end{array}$ & $\begin{array}{c}\text { (2) } \\
\text { Past year } \\
\text { participation }\end{array}$ & $\begin{array}{c}\text { (3) } \\
\text { Past year } \\
\text { disorder }\end{array}$ & $\begin{array}{c}\text { (4) } \\
\text { Past year } \\
\text { disorder } \\
\text { conditional } \\
\text { on past year } \\
\text { use }\end{array}$ \\
\hline Alcohol & 51.39 & 66.09 & 7.96 & 12.05 \\
\hline Marijuana & 6.49 & 11.06 & 2.46 & 22.28 \\
\hline Any Illicit Drug & 3.56 & 8.20 & 1.65 & 19.85 \\
\hline Cocaine & 0.76 & 2.08 & 0.56 & 26.92 \\
\hline Crack & 0.20 & 0.46 & -- & -- \\
\hline Stimulants & 0.44 & 1.16 & 0.22 & 16.39 \\
\hline Methamphetamine & 0.19 & 0.44 & -- & -- \\
\hline Analgesics & 1.93 & 4.77 & 0.82 & 17.20 \\
\hline Oxycodone & 0.16 & 0.59 & -- & -- \\
\hline Heroin & 0.09 & 0.20 & 0.14 & 61.39 \\
\hline Hallucinogens & 0.44 & 1.66 & 0.15 & 8.98 \\
\hline LSD & 0.06 & 0.32 & -- & -- \\
\hline PCP & 0.02 & 0.06 & -- & -- \\
\hline Ecstasy & 0.23 & 0.96 & -- & -- \\
\hline $\begin{array}{l}\text { Sedatives and } \\
\text { Tranquilizers }\end{array}$ & 0.83 & 2.28 & 0.28 & 67.9 \\
\hline Inhalants & 0.25 & 0.81 & 0.06 & 7.75 \\
\hline
\end{tabular}


Table 2: Means, Demographics and Economic Conditions

\begin{tabular}{lccc}
\hline & $(1)$ & $(2)$ & $(3)$ \\
& All & Males & Females \\
\hline Share age 12-17 & 9.97 & 10.50 & 9.46 \\
Share age 18-64 & 74.94 & 76.06 & 73.89 \\
Share age 65+ & 15.10 & 13.44 & 16.66 \\
& & & \\
White & 80.55 & 81.38 & 79.76 \\
Black & 12.21 & 11.44 & 12.93 \\
Other race & 7.25 & 7.18 & 7.31 \\
& & & \\
High school degree or less & 52.00 & 52.89 & 51.16 \\
Some college or more & 48.00 & 47.11 & 48.84 \\
& & & \\
Married & 49.17 & 50.82 & 47.62 \\
Employed & 56.97 & 62.88 & 51.41 \\
State unemployment rate & 6.69 & & 6.69 \\
N & 812,300 & 6.69 & 420,600 \\
\hline Notes: Figures shown are percents. Based on data from the 2002-2013 National Survey on Drug \\
Use and Health. Weighted means are reported. N $812,300$.
\end{tabular}


Table 3: Economic Conditions and Substance Use Participation, Major Drug Classes

NSDUH 2002-2013, coefficient on state unemployment rate

\begin{tabular}{|c|c|c|c|c|}
\hline & $\begin{array}{c}(1) \\
\text { Any past } \\
\text { month use }\end{array}$ & $\begin{array}{c}(2) \\
\text { Any past } \\
\text { month use }\end{array}$ & $\begin{array}{c}\text { (3) } \\
\text { Any past } \\
\text { year use }\end{array}$ & $\begin{array}{l}(4) \\
\text { Any past } \\
\text { year use }\end{array}$ \\
\hline Alcohol & $\begin{array}{c}-.195 \\
(.162)\end{array}$ & $\begin{array}{c}-.343^{* *} \\
(.162)\end{array}$ & $\begin{array}{c}.068 \\
(.165)\end{array}$ & $\begin{array}{l}-.074 \\
(.199)\end{array}$ \\
\hline Marijuana & $\begin{array}{c}.050 \\
(.072)\end{array}$ & $\begin{array}{c}.012 \\
(.068)\end{array}$ & $\begin{array}{c}.055 \\
(.085)\end{array}$ & $\begin{array}{c}-.052 \\
(.096)\end{array}$ \\
\hline Any Illicit Drug & $\begin{array}{c}.021 \\
(.030)\end{array}$ & $\begin{array}{c}-.022 \\
(.028)\end{array}$ & $\begin{array}{c}.019 \\
(.061)\end{array}$ & $\begin{array}{c}.042 \\
(.073)\end{array}$ \\
\hline Cocaine & $\begin{array}{c}-.014 \\
(.023)\end{array}$ & $\begin{array}{l}-.042 * \\
(.021)\end{array}$ & $\begin{array}{l}.016 \\
(.036)\end{array}$ & $\begin{array}{c}-.025 \\
(.033)\end{array}$ \\
\hline Stimulants & $\begin{array}{c}-.030 * * \\
(.013)\end{array}$ & $\begin{array}{c}-.027 * * * \\
(.010)\end{array}$ & $\begin{array}{l}.026 \\
(.038)\end{array}$ & $\begin{array}{l}-.038 \\
(.031)\end{array}$ \\
\hline Analgesics & $\begin{array}{c}.014 \\
(.018)\end{array}$ & $\begin{array}{c}.002 \\
(.024)\end{array}$ & $\begin{array}{c}-.012 \\
(.039)\end{array}$ & $\begin{array}{c}-.011 \\
(.039)\end{array}$ \\
\hline Heroin & $\begin{array}{l}.006 \\
(.005)\end{array}$ & $\begin{array}{l}.009 * \\
(.005)\end{array}$ & $\begin{array}{c}.018 \\
(.013)\end{array}$ & $\begin{array}{l}.010 \\
(.011)\end{array}$ \\
\hline Hallucinogens & $\begin{array}{l}.028 * * \\
(.012)\end{array}$ & $\begin{array}{c}.004 \\
(.012)\end{array}$ & $\begin{array}{l}.076^{*} \\
(.039)\end{array}$ & $\begin{array}{l}.059 * \\
(.031)\end{array}$ \\
\hline $\begin{array}{l}\text { Sedatives and } \\
\text { Tranquilizers }\end{array}$ & $\begin{array}{c}.013 \\
(.016)\end{array}$ & $\begin{array}{c}.012 \\
(.015)\end{array}$ & $\begin{array}{l}.019 \\
(.039)\end{array}$ & $\begin{array}{l}.037 \\
(.035)\end{array}$ \\
\hline Inhalants & $\begin{array}{c}-.00001 \\
(.006)\end{array}$ & $\begin{array}{c}-.006 \\
(.007) \\
\end{array}$ & $\begin{array}{c}.007 \\
(.006) \\
\end{array}$ & $\begin{array}{l}-.015 \\
(.015)\end{array}$ \\
\hline State linear trends & no & yes & no & yes \\
\hline
\end{tabular}

Notes: Based on data from the 2002-2013 National Survey on Drug Use and Health. Marginal probabilities (multiplied by 100) from separate weighted logistic regressions of disorders on the state unemployment rate are reported. Standard errors corrected for clustering at the state level are in parentheses. Although not shown, controls for individual demographic characteristics and state and year fixed effects are included. $\mathrm{N}=812,300$ for all models. Statistical significance is dentoted by *, **, and $* * *$ at the $10 \%, 5 \%$ and $1 \%$ levels, respectively. 
Table 4: Economic Conditions and Substance Use Participation, Drug Subcategories

NSDUH 2002-2013, coefficient on state unemployment rate

\begin{tabular}{|c|c|c|c|c|}
\hline & $\begin{array}{c}(1) \\
\text { Any past } \\
\text { month use }\end{array}$ & $\begin{array}{c}(2) \\
\text { Any past } \\
\text { month use }\end{array}$ & $\begin{array}{c}\text { (3) } \\
\text { Any past } \\
\text { year use }\end{array}$ & $\begin{array}{c}\text { (4) } \\
\text { Any past } \\
\text { year use }\end{array}$ \\
\hline Crack & $\begin{array}{c}-.015 \\
(.010)\end{array}$ & $\begin{array}{l}.021^{*} \\
(.011)\end{array}$ & $\begin{array}{c}-.003 \\
(.018)\end{array}$ & $\begin{array}{l}.043^{* *} \\
(.018)\end{array}$ \\
\hline Meth & $\begin{array}{l}-.007 \\
(.005)\end{array}$ & $\begin{array}{l}-.004 \\
(.006)\end{array}$ & $\begin{array}{l}-.013 \\
(.013)\end{array}$ & $\begin{array}{l}-.012 \\
(.017)\end{array}$ \\
\hline Oxycodone & $\begin{array}{c}.005 \\
(.007)\end{array}$ & $\begin{array}{l}-.001 \\
(.008)\end{array}$ & $\begin{array}{l}.027 * * \\
(.014)\end{array}$ & $\begin{array}{c}.004 \\
(.017)\end{array}$ \\
\hline LSD & $\begin{array}{l}-.007 * * \\
(.003)\end{array}$ & $\begin{array}{l}-.011 * * * \\
(.004)\end{array}$ & $\begin{array}{c}.001 \\
(.012)\end{array}$ & $\begin{array}{l}-.015^{*} \\
(.008)\end{array}$ \\
\hline PCP & $\begin{array}{l}-.0003 \\
(.003)\end{array}$ & $\begin{array}{l}-.006 * \\
(.003)\end{array}$ & $\begin{array}{c}.001 \\
(.004)\end{array}$ & $\begin{array}{l}-.006 * \\
(.003)\end{array}$ \\
\hline Ecstasy & $\begin{array}{l}.028 * * * \\
(.011)\end{array}$ & $\begin{array}{l}.022 * * \\
(.010)\end{array}$ & $\begin{array}{r}.054^{*} \\
(.030) \\
\end{array}$ & $\begin{array}{l}.049 * * * \\
(.019)\end{array}$ \\
\hline State linear trends & no & yes & no & yes \\
\hline 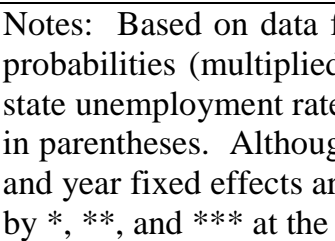 & $\begin{array}{l}\text { n the } 2002-20 \\
100) \text { from se } \\
\text { e reported. Sta } \\
\text { ot shown, con } \\
\text { cluded. } \mathrm{N}=8 \\
0,5 \% \text { and } 1 \%\end{array}$ & $\begin{array}{l}\text { Jational Surve } \\
\text { te weighted lc } \\
\text { rd errors corre } \\
\text { for individual } \\
00 \text { for all mod } \\
\text { to }\end{array}$ & $\begin{array}{l}\text { Drug Use a } \\
\text { regression } \\
\text { or clusterin } \\
\text { ographic ch } \\
\text { tatistical si }\end{array}$ & $\begin{array}{l}\text { lth. Marginal } \\
\text { sorders on the } \\
\text { state level are } \\
\text { istics and state } \\
\text { ice is dentoted }\end{array}$ \\
\hline
\end{tabular}


Table 5: Economic Conditions and Clinical Substance Use Disorders NSDUH 2002-2013, coefficient on state unemployment rate

(1) (2)

Any past year disorder Any past year disorder

with the substance with the substance

\begin{tabular}{lcc}
\hline Alcohol & $.160^{* *}$ & .106 \\
& $(.073)$ & $.081)$ \\
Marijuana & .066 & .048 \\
& $.047)$ & $(.034)$ \\
Any Illicit Drug & .036 & .036 \\
& $(.022)$ & $(.029)$ \\
Cocaine & -.009 & -.017 \\
& $(.011)$ & $. .018)$ \\
Stimulants & .006 & .006 \\
& $(.007)$ & $(.010)$ \\
Analgesics & $.039^{* *}$ & $.049 * *$ \\
& $(.016)$ & $(.020)$ \\
Heroin & .013 & .009 \\
& $(.009)$ & $(.010)$ \\
Hallucinogens & $.022^{* *}$ & $.017 *$ \\
& $(.009)$ & $(.010)$ \\
Sedatives and & .008 & .008 \\
Tranquilizers & $(.010)$ & $(.011)$ \\
Inhalants & -.002 & -.003 \\
\hline State linear trends & $(.004)$ & $(.004)$ \\
\hline No & yes \\
\hline
\end{tabular}

Notes: Based on data from the 2002-2013 National Survey on Drug Use and Health. Marginal probabilities (multiplied by 100) from separate weighted logistic regressions of disorders on the state unemployment rate are reported. Standard errors corrected for clustering at the state level are in parentheses. Although not shown, controls for individual demographic characteristics and state and year fixed effects are included. $\mathrm{N}=812,300$ for all models. Statistical significance is dentoted by *, **, and $* * *$ at the $10 \%, 5 \%$ and $1 \%$ levels, respectively. 
Table 6: Extensions and Robustness Checks, Substance Use Disorder Results Outcome is any disorder unless otherwise noted

\begin{tabular}{|c|c|c|c|c|}
\hline & \multirow{2}{*}{\multicolumn{2}{|c|}{$\begin{array}{l}\text { (1) } \\
\text { Analgesics }\end{array}$}} & \multicolumn{2}{|c|}{ (3) (4) } \\
\hline & & & Hallu & ogens \\
\hline 1) Any disorder (baseline) & $\begin{array}{l}.039 * * \\
(.016)\end{array}$ & $\begin{array}{l}.049 * * \\
(.020)\end{array}$ & $\begin{array}{l}.022 * * \\
(.009)\end{array}$ & $\begin{array}{l}.017 * \\
(.010)\end{array}$ \\
\hline 2) Mild disorder & $\begin{array}{l}.016 \\
(.014)\end{array}$ & $\begin{array}{l}.040 * * * \\
(.014)\end{array}$ & $\begin{array}{l}.011^{* *} \\
(.005)\end{array}$ & $\begin{array}{l}.006 \\
(.006)\end{array}$ \\
\hline 3) Moderate disorder & $\begin{array}{l}.010 \\
(.006)\end{array}$ & $\begin{array}{l}.005 \\
(.009)\end{array}$ & $\begin{array}{l}.003 \\
(.004)\end{array}$ & $\begin{array}{l}.004 \\
(.005)\end{array}$ \\
\hline 4) Severe disorder & $\begin{array}{l}.012 * * \\
(.006)\end{array}$ & $\begin{array}{l}.002 \\
(.010)\end{array}$ & $\begin{array}{c}.009 * * * \\
(.002)\end{array}$ & $\begin{array}{c}.009 * * * \\
(.004)\end{array}$ \\
\hline $\begin{array}{l}\text { 5) Any disorder, respondents } \\
\text { without imputed outcomes }\end{array}$ & $\begin{array}{l}.039 * * \\
(.017)\end{array}$ & $\begin{array}{l}.049 * * \\
(.020)\end{array}$ & $\begin{array}{l}.022 * * \\
(.009)\end{array}$ & $\begin{array}{l}.017 * \\
(.010)\end{array}$ \\
\hline $\begin{array}{l}\text { 6) Any disorder, conditional } \\
\text { on past year use }\end{array}$ & $\begin{array}{l}.823 * * \\
(.355)\end{array}$ & $\begin{array}{l}1.02 * * * \\
(.387)\end{array}$ & $\begin{array}{l}.575 * \\
(.306)\end{array}$ & $\begin{array}{c}.267 \\
(.360)\end{array}$ \\
\hline $\begin{array}{l}\text { 7) Any disorder, linear } \\
\text { probability model }\end{array}$ & $\begin{array}{l}.039 * * \\
(.017)\end{array}$ & $\begin{array}{l}.051 * * \\
(.021)\end{array}$ & $\begin{array}{l}.020 * * \\
(.010)\end{array}$ & $\begin{array}{l}.016 \\
(.010)\end{array}$ \\
\hline $\begin{array}{l}\text { 8) Any disorder, probit } \\
\text { (marginal effects) }\end{array}$ & $\begin{array}{l}.038 * * \\
(.017)\end{array}$ & $\begin{array}{l}.049 * * \\
(.021)\end{array}$ & $\begin{array}{l}.022 * * \\
(.009)\end{array}$ & $\begin{array}{l}.017^{*} \\
(.010)\end{array}$ \\
\hline $\begin{array}{l}\text { 9) Any disorder, using state } \\
\text { employment/population ratio }\end{array}$ & $\begin{array}{l}-.012 \\
(.015)\end{array}$ & $\begin{array}{c}.011 \\
(.019)\end{array}$ & $\begin{array}{c}-.017 * * \\
(.008)\end{array}$ & $\begin{array}{l}-.0002 * \\
(.0001)\end{array}$ \\
\hline $\begin{array}{l}\text { 10) Any disorder, using state } \\
\text { log GDP per capita }\end{array}$ & $\begin{array}{l}-.009 * \\
(.005)\end{array}$ & $\begin{array}{l}-.017 * * \\
(.008)\end{array}$ & $\begin{array}{l}-.002 \\
(.002)\end{array}$ & $\begin{array}{l}-.002 \\
(.002)\end{array}$ \\
\hline $\begin{array}{l}\text { 11) DSM-4 Abuse or } \\
\text { Dependence }\end{array}$ & $\begin{array}{l}.034 * * \\
(.013)\end{array}$ & $\begin{array}{l}.032 * \\
(.016)\end{array}$ & $\begin{array}{l}.015 \\
(.010)\end{array}$ & $\begin{array}{l}.005 \\
(.010)\end{array}$ \\
\hline Linear state trends & no & Yes & no & yes \\
\hline
\end{tabular}

Notes: Based on data from the 2002-2013 National Survey on Drug Use and Health. Marginal probabilities (multiplied by 100) from separate weighted logistic regressions (except for rows 7 and 8 , as described) of disorders on the state unemployment rate are reported (except for rows 9 and 10, as described). Standard errors corrected for clustering at the state level are in parentheses. Although not shown, individual demographic characteristics and state and year fixed effects are included. $\quad \mathrm{N}=812,300$ for all models. Estimates of models with trends for the county level measures to be included in final draft. Statistical significance is dentoted by *,**, and *** at the $10 \%, 5 \%$ and $1 \%$ levels, respectively. 
Table 7: Heterogeneity, Substance Use Disorder Results

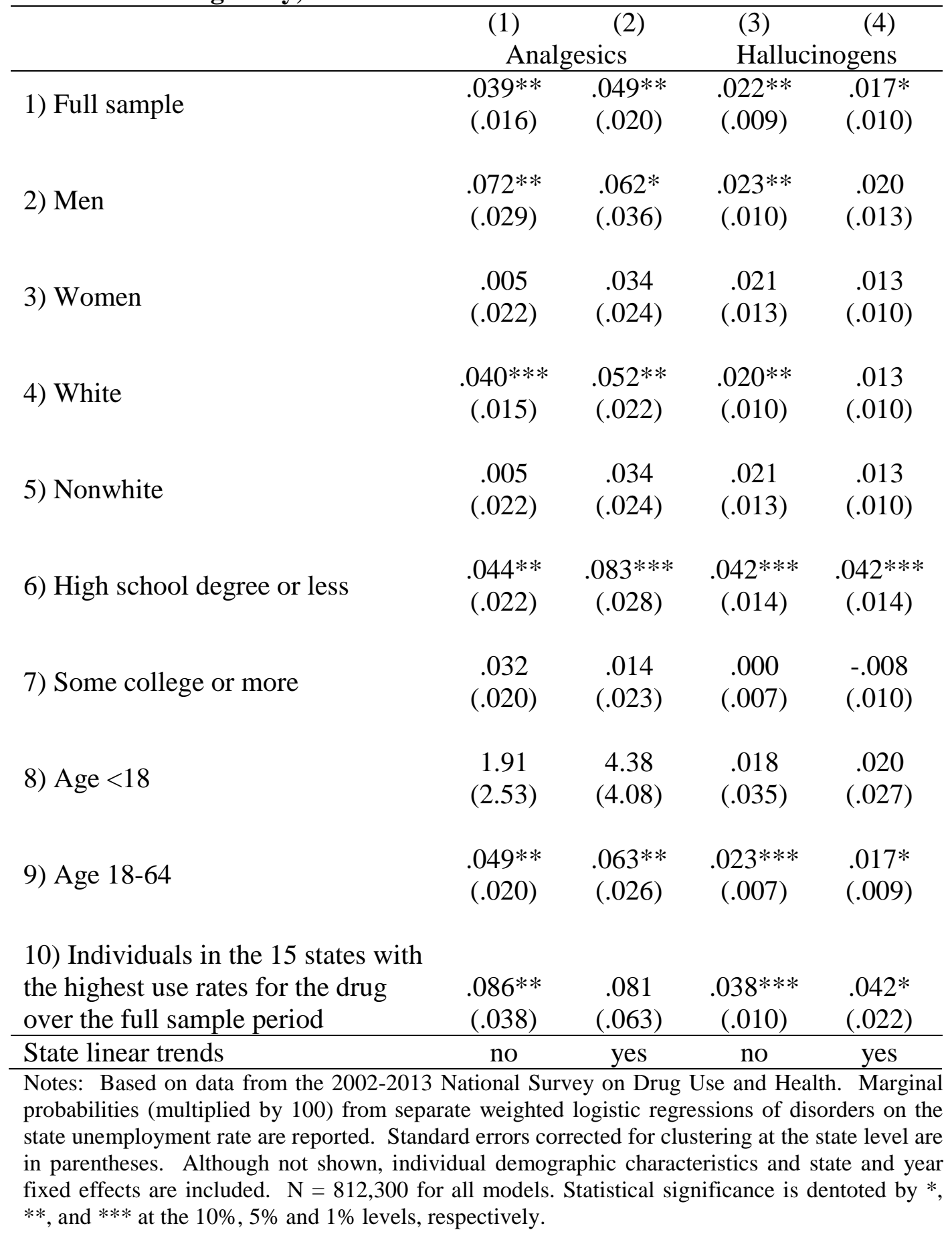


Table 8: Did the Relationship Change During the Great Recession?

$\begin{array}{cc}(1) & (2) \\ \text { Analgesics } & \text { Hallucinogens }\end{array}$

Unemployment Rate

$.087 * * * \quad .022 * *$

$(.031)$

$(.011)$

Great Recession Period (Dec 2007-June 2009)

.001

.0005

(.004)

$(.001)$

Unemployment Rate* Great Recession Period

.030

$-.011$

$(.048)$

$(.015)$

Notes: Based on data from the 2002-2013 National Survey on Drug Use and Health. Marginal probabilities (multiplied by 100) from separate weighted logistic regressions of disorders are reported. Standard errors corrected for clustering at the state level are in parentheses. Although not shown, individual demographic characteristics and state and year fixed effects are included. $\mathrm{N}$ $=812,300$ for all models. Statistical significance is dentoted by *, **, and *** at the $10 \%, 5 \%$ and $1 \%$ levels, respectively. 